\title{
Platelet-Rich Fibrin: Its Role in Advanced Surgical Dentistry-A Review
}

\section{Sumedha Srivastava1*, Veena Kalburgi², Kapil Jain ${ }^{3}$, Shreya Modi, Anushri Gupta5, Rachalwar Shweta Rajendra ${ }^{6}$}

${ }^{1}$ Reader, Department of Periodontology, Peoples College of Dental Sciences and Research Centre, Bhopal (M.P.), India.

2 Professor \& HOD, Department of Periodontology, Peoples College of Dental Sciences and Research Centre, Bhopal (M.P.), India.

${ }^{3}$ Professor, Department of Periodontology, Peoples College of Dental Sciences and Research Centre, Bhopal (M.P.), India.

${ }^{4}$ Post Graduate student II Year, Peoples College of Dental Sciences and Research Centre, Bhopal (M.P.), India.

${ }_{5}^{5}$ Post Graduate Student I Year, Peoples College of Dental Sciences and Research Centre, Bhopal (M.P.), India. ${ }^{6}$ Post Graduate Student II Year, Peoples College of Dental Sciences and Research Centre, Bhopal (M.P.), India.

\section{$\underline{\text { Review article }}$}

\section{Address for Correspondence Author}

Dr. Sumedha Srivastava; Reader, Department of Periodontology, Peoples College of Dental Sciences and Research Centre, Bhopal (M.P.), India.

E-mail: drsumi0109@gmail.com

Crossref doi: https://doi.org/10.36437/ijdrd.2020.2.2.Q

\section{ABSTRACT}

The healing of hard and soft tissue is mediated by a wide range of intracellular and extracellular events that are regulated by signaling proteins. Platelets can play a crucial role in periodontal regeneration as they are the reservoirs of growth factors and cytokines which are the key factors for regeneration of bone and maturation of soft tissue. PRF is a natural fibrin-based biomaterial prepared from an anticoagulant-free blood harvest without any artificial biochemical modification that allows obtaining fibrin membranes enriched with platelets and growth factors. The main aim of this review article is to briefly describe the novel platelet concentrate PRF and its potential role in advanced surgical dentistry.

Keywords: Growth Factors, Periodontal Regeneration, Platelet Concentrates, Platelet-Rich Fibrin.

\section{Introduction}

The prospect of having new therapies, biomaterials, and bioactive surgical additives available that will improve the success and predictability of patient outcomes in soft and bone tissue healing and regeneration are key treatment objectives in dental implantology, periodontology, and oral surgery. Wound healing is initiated by clot formation, followed by proliferative stage which consists of epithelialization, angiogenesis, granulation tissue formation, collagen deposition and finally collagen maturation and contraction. ${ }^{1}$ The disruption of the 
vasculature during wound healing leads to fibrin formation, platelet aggregation, and release of several growth factors into tissues from platelets through molecular signals which are primarily mediated by cytokines and growth factors. ${ }^{2}$ There is evidence that the presence of growth factors and cytokines in platelets play key roles in inflammation and wound healing. ${ }^{3}$ This has led to the idea of using platelets as therapeutic tools to improve tissue repair particularly in periodontal wound healing. Platelet Rich Fibrin (PRF), a patient blood-derived and autogenous living biomaterial are increasingly being investigated and used worldwide by clinicians as an adjunctive autologous biomaterial to promote bone and soft tissue healing and regeneration. The gold standard for in vivo tissue healing and regeneration requires the mutual interaction between a scaffold (fibrin matrix), platelets, growth factors, leukocytes, and stem cells. ${ }^{4}$ These key elements are all active components of PRF and are involved in the key processes of tissue healing and regeneration, including cell proliferation and differentiation, extracellular matrix synthesis, chemotaxis, and angiogenesis (neovascularization) ${ }^{5}$. PRF is superior to other platelet concentrates like PRP due to its ease and inexpensive method of preparation and also it does not need any exogenous compounds like bovine thrombin and calcium chloride. It is advantageous than autogenous graft because an autograft requires a second surgical site and procedure.

Thus, PRF has emerged as one of the promising regenerative materials in the field of periodontics. This review article explains the novel platelet concentrate PRF, its preparation, clinical applications and benefits, and drawbacks over other biomaterials.

\section{What is PRF?}

$\mathrm{PRF}$ is an autologous fibrin-based (membrane, matrix, or scaffold), living biomaterial, derived from human blood, ${ }^{6}$ also referred to as an optimized blood clot.7 ${ }^{7 n}$ essence, PRF is a natural (autologous) composite biomaterial, consisting of fibrin, platelets, growth factors, and various cell types including leukocytes and stem cells. The blood concentrate which is obtained after centrifugation has three distinct layers: a red blood cell (RBC) base at the bottom, a PRF clot in the middle, and an acellular plasma (platelet-poor plasma [PPP]) supernatant layer at the top. The PRF clot is composed of two main parts observable with the naked eye: a fibrin yellow portion, constituting the main body, and a red portion located at the end of the clot (full of RBCs). Between these two areas, a whitish layer "buffy coat" can be observed with the naked eye. PRF can be used directly as a clot, or after compression, as a membrane or plug. Alternatively, the supernatant can be aspirated from the vacutainer (i-PRF) and used in injectable form.

The purpose of PRF technology is to extract essential elements from patients' blood samples, that could be used to improve healing, promote tissue regeneration, and to prepare it in a clinically usable form as a membrane (APRF, L-PRF or CGF) or injectable liquid (i-PRF). The key elements are the fibrin (serving as a supporting matrix), the platelets (rich in growth factors), and cells (mostly the various populations of leukocytes, and stem cells for their antibacterial, neo-vascularization and regenerative properties). ${ }^{8}$ The three-dimensional fibrin membrane creates the scaffold for cells to function optimally during healing and regeneration. The fibrin matrix contains the platelets, leukocytes, growth factors and stem cells that act in synergy to stimulate, improve and accelerate tissue healing and to regenerate soft or bone tissue, including cell proliferation and differentiation, extracellular matrix synthesis, chemotaxis, and angiogenesis. ${ }^{4}$ The purpose of the PRF membrane is to connect the various elements within the fibrin matrix with local tissues (bone and soft tissue), to accelerate neo-angiogenesis thereby enhancing healing and regeneration.

\section{Historical Background}

One of the latest innovations in advanced surgical dentistry is the use of platelet concentrates for in vivo tissue engineering applications. Two types of such platelet concentrates are available: (1) platelet-rich plasma (PRP) 
and (2) platelet-rich fibrin (PRF). These are a concentrated suspension of growth factors found in platelets that act as bioactive surgical additives when applied locally to induce wound healing. ${ }^{9}$ Whitman et al. ${ }^{10}$ in 1997 introduced, the use of PRP in oral surgical procedures proved to enhance cellular proliferation but also carried potential risk due to the generation of antibodies against factors $\mathrm{V}, \mathrm{XI}$, and thrombin, leading to coagulopathies that may endanger life. In 2006, Choukroun and co-workers developed a novel technique with the aim of simplifying the PRP preparation protocol and to eliminate Xeno factors (bovine thrombin). ${ }^{11}$ This led to the socalled "second generation platelet-derived biomaterials" designated as platelet-rich fibrin (PRF) or Choukroun's PRF.

Choukroun's PRF is derived from the patient's own blood and contains a variety of blood cells - including platelets, B- and T-lymphocytes, monocytes, stem cells, and neutrophilic granulocytes - as well as growth factors. ${ }^{12}$ Choukroun modified his PRF to produce A-PRF (leukocyte-enriched, advanced type) and i-PRF (injectable PRF) ${ }^{13,14}$ by reducing the centrifuge speed; leukocyte infiltration into the red blood cell fraction is minimized. Both A-PRF and i-PRF preparations are characterized by platelets, leukocytes and circulating stem cells, and endothelial cells concentrated in the fibrin clot. Leukocytes are enriched in A-PRF ${ }^{14}$ and L-PRF ${ }^{15}$, to exploit their antibacterial and osteoconductive activity.

\section{Classification of Platelet Concentrates}

Recently a full classification of platelet concentrate technologies was suggested ${ }^{16}$ that allowed classifying the main available techniques in 4 families depending on their leukocyte content and fibrin architecture:

A. Pure Platelet-Rich Plasma (P-PRP) - Liquid suspension without leukocytes before activation. (Can be activated and transformed into a gel form - P-PRP gel).

B. Leukocyte- and Platelet-Rich Plasma (L-PRP) - Liquid suspension with leukocytes before activation. (Can be activated and transformed into a gel form — L-PRP gel).

C. Pure Platelet-Rich Fibrin (P-PRF) (i.e. Fibrinet) - Solid fibrin material without leukocytes.

D. Leukocyte- and Platelet-Rich Fibrin i.e. Choukrouns PRF; Advanced PRF, (A-PRF), and injectable iPRF; L-PRF; and Concentrated Growth Factors (CGF) — Solid fibrin material with leukocytes.

\section{Protocols for Platelet-Rich Fibrin Preparation Blood Drawing}

A major advantage of PRF is that it has a simple preparation protocol. Blood is drawn from the patient using a sterile $10 \mathrm{ml}$ vacutainer just before or during surgery. The tubes with collected blood samples are immediately (within 2 minutes after collecting the blood sample) placed in the centrifuge and processed using a single centrifugation step. The clinical success of the PRF protocol is dependent on a quick collection of blood and its transfer to the centrifuge because blood will automatically start to coagulate after 1-2 minutes and make it difficult to obtain the required clot quality ${ }^{17}$ Failure to accomplish the quick preparation of PRF could cause a diffuse polymerization of fibrin, which is not ideal for tissue healing.

\section{Centrifugations}

The tubes should always be balanced by opposing two tubes to equilibrate the centrifugation forces and to prevent vibrations during the centrifugation process. At the end of the centrifugation spin, the caps for A-PRF or L-PRF (not i-PRF) are removed and the tubes placed in a sterile tube holder. The blood sample with the clot is allowed to rest/mature for approximately 4-8 minutes before extracting the clot from the tube. The centrifugation process activates the coagulation process and separates the blood sample into three different layers: an acellular plasma at the top of the tube; a strongly polymerized fibrin clot is formed in the middle; and blood cells (red corpuscle base) are gathered at the bottom of the tube.18,19 


\section{Currently Used Centrifugation Protocols}

* Original Choukroun's PRF protocol (standard protocol): 3,000 rpm/10 minutes.

* Dohan Ehrenfest's group (leukocyte- and platelet-rich fibrin [L-PRF]): 2,700 rpm/12 minutes.

* Choukroun's advanced PRF (A-PRF), enriched with leukocytes: 1,300 rpm/ 8 minutes.

* Choukroun's i-PRF (solution/gel): 700 rpm/3 minutes.

\section{Uses of Platelet Rich Fibrin in Advanced Surgical Dentistry}

A form of PRF i.e fibrin plug or membrane is used as a filler material in extraction sockets to prevent complications and to enhance socket healing. PRF can also be used as a protective barrier membrane to seal off and promote healing of oroantral communications following extractions; to close a palatal connective tissue harvesting site; or as sole grafting material in the sinus floor elevations or as a Vestibuloplasty wound bandage.20,21 PRF (membrane or liquid) can be added or mixed to bone substitutes like xenograft or biphasic calcium phosphate (BCP) to enhance the formation of new bone. ${ }^{22}$

\section{Periodontal Regeneration}

Local application of growth factors promotes periodontal regeneration and healing. Yuchao et al. ${ }^{23}$ showed that the use of PRF as the sole grafting material to be an effective modality of regenerative treatment for periodontal intrabony defects. PRF could serve as a resorbable membrane for guided bone regeneration, preventing the migration of nondesirable cells into a bony defect and providing a space that allows the immigration of osteogenic and angiogenic cells, and permits the underlying blood clot to mineralize. The concept of "natural bone regeneration" was proposed by Simonpieri et al. ${ }^{24}$ which includes regeneration of gingival tissue and bone volume through PRF membrane.

\section{Sinus Lift}

A sinus floor elevation is a technique to increase the residual bone height of the posterior edentulous maxilla. PRF can be used in sinus lift procedures in two ways, either as fragments mixed with different bone substitutes like autogenous bone graft, xenogeneic, allogeneic, and some artificial materials or as a sole filling material. ${ }^{25}$

\section{Gingival Recession}

Coronally advanced flap procedure with sub-epithelial connective tissue is the most predictive plastic procedure. Recently, PRF has been used along with conventional order to improve the efficiency of the root coverage treatments and reduce the morbidity of the techniques. Aroca et al., ${ }^{26}$ stated that use of PRF membrane cause an increase in the width of keratinized gingival at the test sites at 6 months compared to the modified coronally advanced flap alone.

\section{Perio-Endo Lesions}

Perio-endo lesions develop by either periodontal lesion spreading apically with an already existing periapical lesion or an endodontic lesion combining with an existing periodontal lesion. The prognosis of a true combined perio-endo lesion is poor or even hopeless, especially if it is chronic in nature. The prognosis of such affected tooth can be improved by increasing the bony support through bone grafting and guided tissue regeneration and the application of polypeptide growth factors to the surgical wound. ${ }^{27}$ El-Sharkawy et al. ${ }^{28}$ suggested the administration of PRF along with tissue regeneration methods for the repair of intrabony defects, furcations, and periapical cystic cavities. 


\section{Drawbacks of PRF}

The main shortcoming of PRF is its preparation and storage. ${ }^{29}$ The clinical benefit of PRF depends on the time interval between the speed of handling between blood collection and centrifugation as PRF is prepared without adding any anticoagulants. Also, PRF membrane is used immediately after preparation as it will shrink resulting in dehydration altering the structural integrity of PRF. Dehydration also results in the decreased growth factor content in $\mathrm{PRF}^{30}$ and leukocyte viability will be adversely affected altering its biologic properties. PRF when stored in a refrigerator can result in the risk of bacterial contamination of the membranes. These limitations with the use of PRF can be circumvented by sticking onto a standard protocol for preparation and preservation.

\section{Conclusion}

PRF by Choukroun's technique is a simple and inexpensive technique for the successful regeneration of periodontal tissues. The main advantage is that PRF preparation utilizes the patient's own blood reducing or eliminating disease transmission through blood. In the future more studies and clinical trials are needed to investigate potential applications of PRF in the field of periodontal regeneration and tissue engineering and to extend its clinical applications.

\section{References}

1. Agrawal M, Agrawal V. Platelet rich fibrin and its applications in dentistry-A review article. Natl J Med Dent Res 2014; 2:51-8.

2. Deodhar AK, Rana RE. Surgical physiology of wound healing: a review. J Postgrad Med 1997; 43:52-6.

3. Giannobile WV. Periodontal tissue engineering by growth factors. Bone 1996; 19(Suppl. 1):23S37S. https://doi.org/10.1016/S8756-3282(96)00127-5

4. Kawase T. Platelet-rich plasma and its derivatives as promising bioactive materials for regenerative medicine: basic principles and concepts underlying recent advances. Odontology 2015; 103: 126-135. https://doi.org/10.1007/s10266-015-0209-2

5. Dohan Ehrenfest DM, Bielecki T, Mishra A, Borzini P, Inchingolo F, Sammartino G, Rasmusson L, Evert PA. In search of a consensus terminology in the field of platelet concentrates for surgical use: platelet-rich plasma (PRP), platelet-rich fibrin (PRF), fibrin gel polymerization and leukocytes. Curr Pharm Biotechnol. 2012; 13(7): 1131- 1137.

6. Prakash S, Thakur A. Platelet concentrates: past, present and future. J Maxillofac Oral Surg 2011; 10: 45-49. https://dx.doi.org/10.1007\%2Fs12663-011-0182-4

7. Del Corso M, Dohan Ehrenfest DM. Immediate implantation and peri-implant Natural Bone Regeneration (NBR) in the severely resorbed posterior mandible using Leukocyte- and PlateletRich Fibrin (L-PRF): a 4-year follow-up. POSEIDO. 2013; 1(2): 109-16.

8. Dohan Ehrenfest DM, Del Corso M, Diss A, Mouhyi J, Charrier JB. Three-dimensional architecture and cell composition of a Choukroun's platelet-rich fibrin clot and membrane. J Periodontol 2010; 81: 546-555. https://doi.org/10.1902/jop.2009.090531

9. Kiran NK, Mukunda KS, Tilak Raj TN. Platelet concentrates: A promising innovation in dentistry. J Dent Sci Res 2011; 2:50-61.

10. Whitman DH, Berry RL, Green DM. Platelet gel: An autologous alternative to fibrin glue with applications in oral and maxillofacial surgery. J Oral Maxillofac Surg 1997; 55:1294-9. https://doi.org/10.1016/S0278-2391(97)90187-7 
11. Dohan DM, Choukroun J, Diss A, Dohan SL, Dohan AJ, Mouhyi J, Gogly B. Platelet-rich fibrin (PRF): A second- generation platelet concentrate. Part I: Technological concepts and evolution. Oral Surg Oral Med Oral Pathol Oral RadiolEndod 2006; 101: e37-44. https://doi.org/10.1016/i.tripleo.2005.07.008

12. Perut F, Filardo G, Mariani E, et al. Preparation method and growth factor content of platelet concentrate influence the osteogenic differentiation of bone marrow stromal cells. Cytotherapy. 2013; 15:830-839. https://doi.org/10.1016/i.jcyt.2013.01.220

13. Ghanaati S, Booms, P, Orlowska B, Kubesch A, Lorentz J, Rutowski J, Landes C, Sader R, Kirkpatric C, Choukroun J/ Advanced Platelet-Rich Fibrin (A-PRF) - A new concept for cell based tissue engineering by means of inflammatory cells. J Oral Implantol. 2014; 40(6): 679-689. https://doi.org/10.1563/aaid-joi-D-14-00138

14. Choukroun J. Advanced PRF \& i-PRF: platelet concentrates or blood concentrates? J Periodont Med Clin Pract. 2014; 1: 3.

15. Dohan Ehrenfest DM. How to optimize the preparation of leukocyte- and platelet-rich fibrin (LPRF, Choukroun's technique) clots and membranes: introducing the PRF Box. Oral Surg Oral Med Oral Pathol Oral Radiol Endod. 2010; 110(3): 275-8. https://doi.org/10.1016/i.tripleo.2010.05.048

16. Dohan Ehrenfest DM, Rasmusson L, Albrektsson T. Classification of platelet concentrates: from pure platelet-rich plasma (P-PRP) to leucocyte- and platelet-rich fibrin (L-PRF). Trends Biotechnol 2009; 27:158-167. https://doi.org/10.1016/j.tibtech.2008.11.009

17. Ali S, Bakry SA, Abd-Elhakam H. Platelet-rich fibrin in maxillary sinus augmentation: a systematic review. J Oral Implantol. 2015; 41(6):746-753. https://doi.org/10.1563/AAID-JOID-14-00167

18. Bajaj P, Pradeep AR, Agarwal E, et al. Comparative evaluation of autologous platelet-rich fibrin and platelet-rich plasma in the treatment of mandibular degree II furcation defects: a randomized controlled clinical trial. J Periodont Res. 2013; 48(5):573-581. https://doi.org/10.1111/ire.12040

19. Barone A, Ricci M, Romanos GE, Tonelli P, Alfonsi F, Covani U. Buccal bone deficiency in fresh extraction sockets: a prospective single cohort study. Clin Oral Implants Res. 2015; 26(7):823830. https://doi.org/10.1111/clr.12369

20. Öncü EA, Erbeyoğlu AA. Enhancement of immediate implant stability and recovery by plateletrich fibrin. Clin Oral Impl Res. 2017; 27. Doi: https://doi.org/10.11607/prd.2505

21. Kanayama T, Sigetomi T, Sato H, Yokoi M. Crestal approach sinus floor elevation in atrophic posterior maxilla using only platelet rich fibrin as grafting material: A computed tomography evaluation of 2 cases. J Oral Maxillofac Surg Med Path. 2014; 26(4):519-525. https://doi.org/10.1016/j.ajoms.2013.05.009

22. Toeroek R, Dohan EDM. The concept of Screw- Guided Bone Regeneration (S-GBR). Part 3: Fast Screw- Guided Bone Regeneration (FS-GBR) in the severely resorbed preimplant posterior mandible using allograft and Leukocyte- and Platelet-Rich Fibrin (L PRF): a 4-year follow-up. POSEIDO. 2013; 1(2):93-100.

23. Yu-Chao C, Kuo-Chin W, Jiing-Huei Z. Clinical application of platelet-rich fibrin as the sole grafting material in periodontal intrabony defects. J Dent Sci 2011; 6:181-8. https://doi.org/10.1016/i.jds.2011.05.010 
24. Simonpieri A, Del Corso M, Vervelle A, Jimbo R, Inchingolo F, Sammartino G, et al. Current knowledge and perspectives for the use of platelet-rich plasma (PRP) and platelet-rich fibrin (PRF) in oral and maxillofacial surgery part 2: Bone graft, implant and reconstructive surgery. Curr Pharm Biotechnol 2012; 13:1231-1256. https://doi.org/10.2174/138920112800624472

25. Hamdoun R, Ennibi OK, Ismaili Z. PRF in oral surgery: A literature review. J Med Implants Surg 2016; 1:110. https://www.omicsonline.org/peer-reviewed/prf-in-oral-surgery-a-literaturereviewp-82960.html

26. Aroca S, Keglevich T, Barbieri B, Gera I, Etienne D. Clinical evaluation of a modified coronally advanced flap alone or in combination with a platelet-rich fibrin membrane for the treatment of adjacent multiple gingival recessions: A 6-month study. J Periodontol 2009; 80:244-52. https://doi.org/10.1902/jop.2009.080253

27. Karunakar P, Prasanna JS, Jayadev M, Shravani GS. Platelet-rich fibrin, "a faster healing aid" in the treatment of combined lesions: A report of two cases. J Indian Soc Periodontol 2014; 18:651-655. https://dx.doi.org/10.4103\%2F0972-124X.142467

28. El-Sharkawy H, Kantarci A, Deady J, Hasturk H, Liu H, Alshahat M, et al. Platelet-rich plasma: Growth factors and pro- and anti-inflammatory properties. J Periodontol 2007; 78:661-669. https://doi.org/10.1902/jop.2007.060302

29. Aroca S, Keglevich T, Barbieri B, Gera I, Etienne D. Clinical evaluation of a modified coronally advanced flap alone or in combination with a platelet-rich fibrin membrane for the treatment of adjacent multiple gingival recessions: A 6-month study. J Periodontol 2009; 80:244-252. https://doi.org/10.1902/jop.2009.080253

30. Dohan Ehrenfest DM, de Peppo GM, Doglioli P, Sammartino G. Slow release of growth factors and thrombospondin-1 in Choukroun's platelet-rich fibrin (PRF): a gold standard to achieve for all surgical platelet concentrates technologies. Growth Factors 2009; 27:63-69.S https://doi.org/10.1080/08977190802636713

How to cite this Article: Sumedha Srivastava ${ }^{1 *}$, Veena Kalburgi ${ }^{2}$, Kapil Jain ${ }^{3}$, Shreya Modi, Anushri Gupta5 ${ }^{5}$ Rachalwar Shweta Rajendra6: Platelet-Rich Fibrin: Its Role in Advanced Surgical Dentistry-A Review

Int. J. Drug Res. Dental Sci., 2020; 2(2):16-22.

Crossref doi: $\underline{\text { https://doi.org/10.36437/ijdrd.2020.2.2.Q }}$

Source of Support: Nil, Conflict of Interest: Nil.

Received: 27-4-020 Revised: 20-5-2020 Accepted: 25-5-2020 